\title{
Factors affecting the course of body and kidney growth in infants with urolithiasis: A critical long-term evaluation
}

\author{
Kemal Sarica $^{1}$, Fatma Narter ${ }^{2}$, Kubilay Sabuncu ${ }^{1}$, Ahmet Akca ${ }^{3}$, Utku Can $^{1}$, Ayşe Buz ${ }^{1}$, \\ H. Nese Sarica ${ }^{4}$, Bilal Eryildirim ${ }^{1}$ \\ ${ }^{1}$ Dr. Lutfi Kirdar Training and Research Hospital Urology Clinic, Istanbul, Turkey; \\ ${ }^{2}$ Dr. Lutfi Kirdar Training and Research Hospital Pediatric Clinic, Istanbul, Turkey; \\ ${ }^{3}$ Dr. Lutfi Kirdar Training and Research Hospital Radiology Clinic, Istanbul, Turkey; \\ ${ }^{4}$ Medistate Hospital, Istanbul, Turkey.
}

\begin{abstract}
Summary Objective: To investigate the possible effects of dietary, patient and stone related factors on the clinical course of the stone disease as well as the body and renal growth status of the infants.

Patients and Methods: A total of 50 children with an history of stone disease during infancy period were studied. Patient (anatomical abnormalities, urinary tract infection - UTI, associated morbidities), stone (obstruction, UTI and required interventions) and lastly dietary (duration of sole breast feeding, formula feeding) related factors which may affect the clinical course of the disease were all evaluated for their effects on the body and renal growth during long-term follow-up. Results: Mean age of the children was $2.40 \pm 2.65$ years. Our findings demonstrated that infants receiving longer period of breast feeding without formula addition seemed to have a higher rate of normal growth percentile values when compared with the other children. Again, higher frequency of UTI and stone attacks affected the growth status of the infants in a remarkable manner than the other cases. Our findings also demonstrated that thorough a close follow-up and appropriately taken measures; the possible growth retardation as well as renal growth problems could be avoided in children beginning to suffer from stone disease during infancy period. Conclusions: Duration of breast feeding, frequency of UTI, number of stone attacks and stone removal procedures are crucial factors for the clinical course of stone disease in infants that may affect the body as well as kidney growth during long-term follow-up.
\end{abstract}

KEY WORDS: Urinary calculi; Kidney; Stone related factors; Infant.

Submitted 7 June 2016; Accepted 19 July 2016

\section{INTRODUCTION}

Although the overall incidence of pediatric urinary stone disease is relatively rare $(1-2 \%)(1,2)$; infantile nephrolithiasis has been reported to be common in countries like Iran, Turkey, Armenia, United Kingdom, Iceland, Iraq, and Italy (3-11). Taking the commonly detected metabolic as well as genitourinary abnormalities and other certain crucial factors that can lead to recurrent stone episodes into account, published data have clearly shown that the disease may reveal morphologic and functional changes in the kidneys indicating the importance of a thorough evaluation as well as close follow-up of every stone forming infant in an individual basis $(3-5,12,13)$.

Regarding the clinical course of the disease; while overall recurrence rates range widely from 6.5 to $44 \%$ without follow-up and appropriate management, these rates have been reported to be as high as $50 \%$ within 5 or 6 years $(2,13-16)$. The rate of stone recurrence in one of our previous reports was $4 \%$ during a 5-year follow-up period (17).

In the light of these data, it is clear that a close follow-up of the clinical course as well as the natural history of urolithiasis in these cases merit great attention. There are sufficient data reported in the literature dealing with the incidence, metabolic abnormalities, recurrence rates and that of spontaneous passage rates in adults (14, 18-20). However, evaluation of the current literature clearly shows the lack of reliable data on the clinical course of urolithiasis particularly in infants with highly limited data concerning the possible crucial factors affecting the disease course in this highly specific population. On the other hand again, the susceptibility of growing body as well as the kidneys of these cases increases the importance of some certain patient and disease related factors which makes the careful monitorization of all children mandatory after the first stone attack.

The aim of the present study is to evaluate the natural course of the stone disease in infants from different perspectives in order to outline the possible adverse affects of certain factors on the body as well as kidney growth.

\section{Patients And methods}

A total of 50 infants (28 boys and 22 girls; M/F: 1.27) with an established primary single calcium oxalate urinary stone (when a calculus was diagnosed by a renal ultrasonography or a spontaneous passage was present) were included and the follow-up file notes were evaluated in detail. Metabolic abnormalities which may significantly affect the clinical course of the disease were noted based on serum and urine related risk factors basically depending on spot urine evaluations. All children with anatomic obstruction, neurogenic disorders and urinary diversions noted in their files were excluded from the 
study program in the beginning. Additionally, infants with kidney failure and genitourinary anomalies and those who were taking drugs that could affect mineral metabolism (corticosteroids, diuretics, and anticonvulsants) were also excluded. In the absence of urinary tract obstruction, infection and hematuria, depending on the size of the stones no child among these 50 cases required an intervention at first referral and they were all taken on a close follow-up program.

Although the majority of the children were followed-up regularly in our center; data of the children coming from other cities were obtained from the referring physicians. Additionally, some of the data concerning the clinical symptomatology, spontaneously passed stones, procedures performed for stone removal were obtained from the parents by way of phone call interviews.

The clinical course of the disease in all children with solitary stones located in renal pelvis were assessed and noted. In addition to the age at first presentation, stone size, positive family history and the results of metabolic evaluation; feeding status of the children (the total duration of breast feeding, beginning of formula feeding), was also carefully recorded. All children were again well evaluated with respect to spontaneous passage rates, required interventions, urinary tract infections and lastly and more importantly the physical as well as the renal growth rates.

After obtaining the past history (including positive family anamnesis); a careful physical examination was performed and biochemical analysis including blood and urine examinations (including culture sensitivity test) were performed in all children. Additionally, they underwent thorough a radio-sonographic investigation of the urinary tract to detect the possible anatomic abnormalities, the presence and the degree of obstruction caused by the stone, and to determine and locate other possible stones. In the majority of the cases, a plain film (KUB) and/or urinary sonography were the initial radiological method to image the stone. Non-contrast helical computerized tomography (NCCT) was performed rarely when necessary (especially in cases with relatively smaller stones and ureteral calculi). As metioned above, as no child among these 50 cases required an intervention at first referral, they were all taken on a close follow-up program with regular visits and necassary evaluations.

Growth retardation was defined as a height Z score below the $2 \mathrm{SD}$ for age and sex and/or below $2 \mathrm{SD}$ than mid-parenteral height SD $(21,22)$. At the same time all of the cases with defined growth retardation were also found to have weight percentiles under 10 . Measurement of renal size (length and width) and parenchymal thickness values were done with renal sonography and comparatively evaluated with respect to the nomograms of renal parenchymal thickness and renal lenght in healthy children. Reduced renal size and/or renal parenchymal thickness were defined with the values obtained below 2SD (23).

The study protocol was approved by the ethics committee of the institution. Written informed consent from the children's parents was obtained before performing any examination or treatment.

NCSS (NumberCruncher Statistical System) 2007\&PASS
(Power Analysis and Sample Size) 2008 Statistical Software (Utah, USA) program has been used for staistical analysis. In addition to the definitive statistical methods (mean, standard deviation, median, frequency, rate, minimum and maximum) used during the evaluation of the data obtained, Mann Whitney U test has also been used for the evaluation of the abnormally distributed parameters between two groups to compare the quantitative data. Lastly, Pearson Chi-Square Test, Fisher's Exact Test, Fisher-Freeman-Halton Test and Yates Continuity Correction tests (Yates corrected Chi-square) were used in the evaluation and comparison of qualitative parameters between the groups. Statistical significance was defined with the levels of $\mathrm{p}<0.01$ and $\mathrm{p}<0.05$.

\section{RESULTS}

In this present study we mainly aimed to evaluate the possible effects of feeding status, urinary tract infections, number of new stone attacks and additional stone removal procedures on the physical as well as renal growth of infants during a long term follow-up period. Data obtained from a total of 50 infants ( 28 boys and 22 girls, M/F: 1.27 , aged 15 days-11,5 years) were recorded. All children had a single radiopaque stone located in renal pelvis at first referral. Stone analysis was done after obtaining a stone sample either after a stone removal procedure (40 cases) or after spontaneous passage of the fragments (10 cases) during close follow-up. Evaluation of the stone composition revealed that the vast majority of the stones were calcium containing ones.

Evaluation of the stone size in both groups revealed similar values with an average value of $3.4 \mathrm{~mm}(2-9 \mathrm{~mm})$. Basic characteristic and clinical variables of the patients evaluated in both groups are shown in Table 1.

Taking the difficulty of 24-h urine collection in these cases into account, metabolic evaluation depended mainly on a spot urine examination. Urinary metabolic data were present in 38 cases. Hypocitraturia alone with hypercalciuria were the most common abnormalities detected.

Table 2 summarizes the outcomes on this aspect. Overall follow-up period in all cases ranged from 4 to 75 months

\section{Table 1.}

Basic characteristic and clinical variables of cases $(n=50)$.

\begin{tabular}{|lcc|}
\hline Birthweight $(\mathrm{g})($ mean \pm SD) (range) & $3027 \pm 767$ & $980-5000$ \\
\hline Birthweight $<10 \mathrm{p}(\mathrm{n}, \%)$ & 8 & 16 \\
\hline Male sex $(\mathrm{n}, \%)$ & 22 & 44 \\
\hline Female sex (n,\%) & 28 & 56 \\
\hline $\begin{array}{l}\text { Duration of breastfeeding (month) } \\
\text { (mean } \pm \text { SD) (range) }\end{array}$ & $5.9 \pm 6.2$ & $(0-24)$ \\
\hline $\begin{array}{l}\text { Time of starting solid food (month) } \\
\text { (mean } \pm \text { SD) (range) }\end{array}$ & $8.6 \pm 4.8$ & $(4-24)$ \\
\hline $\begin{array}{l}\text { Duration of breastfeeding (month) } \\
\text { (mean } \pm \text { SD) (range) }\end{array}$ & $14.0 \pm 10.1$ & $(1-42)$ \\
\hline Additional disease (n,\%) & 9 & 18 \\
\hline Hypertension (n,\%) & 0 & 0 \\
\hline Family history of nephrolitiasis & 37 & 74 \\
\hline Growth retardation & 11 & 22 \\
\hline
\end{tabular}


with an average period of 25 months. Children were divided into two groups depending on the growth percentiles and renal growth status as follows: Group 1 $(n: 11)=$ infants demonstrating growth retardation and/or renal growth failure (1a; growth retardation and lb; renal growth retardation), Group 2 (n:39) = infants with normal growth percentile as well kidney size values. All relevant parameters mentioned above were comparatively evaluated in these two groups. Patient characteristics and the follow-up period in both groups are summarized in Tables 3-5.

During the long-term follow up of these cases, a total of 40 children $(80 \%)$ required stone removal procedures due to the obstruction related problems (pain, infection and hematuria). While 32 cases underwent shock wave lithotripsy (SWL) (80\%), a total of 8 cases (20\%) required ureteroscopy for the removal of symptomatic stones. The remaining 10 cases passed the stone spontaneously without any intervention.

\section{Table 2.}

Metabolic abnormalities in terms of urinary risk factors detected in 38 children.

\begin{tabular}{|lccc|}
\hline Metabolic abnormality & Normal values & $\mathbf{n}$ & $\%$ \\
\hline Decreased urine output & $>20 \mathrm{ml} / \mathrm{kg} /$ day & $20 / 38$ & 52.6 \\
\hline Hypocitraturia & $>400 \mathrm{mg} / \mathrm{g}$ cre/day & $22 / 38$ & 57.8 \\
\hline Hypercalciuria & $<4 \mathrm{mg} / \mathrm{kg} /$ day & $17 / 38$ & 44.7 \\
\hline Hyperoxaluria & $<45 \mathrm{mg} / 1.73 \mathrm{~m}^{2}$ & $3 / 38$ & 7.8 \\
\hline
\end{tabular}

Table 3.

Evaluation of some risk factors according to the growth percentile of the cases.

\begin{tabular}{|c|c|c|c|}
\hline & $\begin{array}{l}\text { Normal growth } \\
\quad(n=39)\end{array}$ & $\begin{array}{l}\text { Retarded growth } \\
\quad(n=11)\end{array}$ & $\mathbf{p}$ \\
\hline Growth retardation at birth $(n, \%)$ & $6(15.4)$ & $1(9.1)$ & 1.000 \\
\hline \multicolumn{4}{|l|}{ Duration of breastfeeding (month) } \\
\hline $\begin{array}{l}\text { mean } \pm \text { SD } \\
\text { range (median) }\end{array}$ & $\begin{array}{c}5.1 \pm 5.04 \\
0-24(6)\end{array}$ & $\begin{array}{l}8.5 \pm 9.1 \\
0-24(6)\end{array}$ & 0.508 \\
\hline Formula use $(n, \%)$ & $22(56.4)$ & $7(63.6)$ & 0.741 \\
\hline \multicolumn{4}{|l|}{ Time of starting solid food (month) } \\
\hline $\begin{array}{l}\text { mean } \pm S D \\
\text { range (median) }\end{array}$ & $\begin{array}{r}8.0 \pm 3.7 \\
4-24(6)\end{array}$ & $\begin{array}{c}10.7 \pm 7.5 \\
5-24(6)\end{array}$ & 0.722 \\
\hline \multicolumn{4}{|l|}{ Duration of breastfeeding (month) } \\
\hline $\begin{array}{l}\text { mean } \pm S D \\
\text { range (median) }\end{array}$ & $\begin{array}{c}14.3 \pm 10.4 \\
1-42(12)\end{array}$ & $\begin{array}{l}13.0 \pm 9.7 \\
1-30(11)\end{array}$ & 0.777 \\
\hline \multicolumn{4}{|l|}{ Urinary tract infections $(n, \%)$} \\
\hline None & $14(35.9)$ & $4(36.4)$ & 0.202 \\
\hline 1 & $14(37.3)$ & $1(9.1)$ & \\
\hline$\geq 3$ & $12(30.8)$ & $6(54.5)$ & \\
\hline \multicolumn{4}{|l|}{ Age of first stone (month) } \\
\hline mean $\pm S D$ & $32.8 \pm 3.45$ & $14.9 \pm 12.60$ & 0.078 \\
\hline range (median) & $0-138(24)$ & $0-36(7)$ & \\
\hline \multicolumn{4}{|l|}{ Stone attack $(n, \%)$} \\
\hline None & $15(38.5)$ & $6(54.5)$ & 0.594 \\
\hline 1 & $18(15.0)$ & $3(27.3))$ & \\
\hline$>1$ & $6(54.5)$ & $2(18.2)$ & \\
\hline \multicolumn{4}{|l|}{ Additional treatment need } \\
\hline None & $7(17.9)$ & $3(27.3)$ & 0.888 \\
\hline ESWL & $26(66.8)$ & $6(54.5)$ & \\
\hline ESWL+ other & $6(15.4)$ & $2(18.2)$ & \\
\hline$\overline{\text { Additional disease }(n, \%)}$ & $6(15.4)$ & $3(27.3)$ & 0.392 \\
\hline
\end{tabular}

Evaluation of our obtained data revealed the following findings:

1. Feeding status of the infants: a careful assessment of the duration of breast feeding and the timing of initiation of formula feeding in infants showed that cases with evident growth retardation status (Height $z$ score below to 2 SDS for age and sex and/or below to 2 SDS than mid-parenteral height SD) seemed to have a shorter total breast feeding time along with longer formula feeding (12 vs 11 month; $75 \%$ vs $56.5 \%$ respectively) (Table 3 ). In other words, stone disease in infants with shorter period of breast feeding seemed to be more complicated with higher number of stone as well as urinary tract infection attacks than the cases with normal growth percentiles ( $>1$ stone attack frequency $18.2 \%$ vs $15.4 \% ; \geq 3$ urinary tract infection attack frequency $54.5 \%$ vs $30.8 \%$ respectively) (Table 3). Infants in whom the formula feeding has been initiated in an earlier manner tended to have more frequent stone and UTI attacks which may affect the growth status of the children during long-term follow-up.

On the other hand again, evaluation of the renal growth status (kidney size as well as renal parenchymal thickness) on this aspect clearly demonstrated the positive effects of breast feeding where children with reduced kidney size and renal parenchymal thickness had a shorter period of sole breast feeding along with an earlier initiation of formula feeding (median exclusively breast feeding duration 6 vs 1 month, median total breast feeding duration 12 vs 8.5 month, formula initiation $56.5 \%$ vs $75 \%$ respectively in children having normal and reduced renal size) (Table 4), (median exclusively breast feeding duration 6 vs 3 month, median total breast feeding duration 14.5 vs 8 month, formula initiation $51.5 \%$ vs $70.6 \%$ respectively in children having normal and reduced renal parenchymal thickness) (Table 5).

2. Frequency of Urinary Tract Infections: Urinary tract infection (UTI) is a certain risk factor which may affect the body and as a result renal growth of the children. Careful assessment of the frequency of UTI attacks in infants clearly showed the negative effect of higher number of UTI's on the growth percentile values where infants demonstrating a normal body growth course had lower number of UTI attacks when compared with cases demonstrating evident retardation $(\geq 3$ urinary tract infections $54.5 \%$ vs $30.8 \%$ ) (Table 3 ). In other words infants with frequent stone related UTI attacks tended to have lower percentile values during long-term follow-up. On the other hand again, evaluation of the renal growth status (kidney size) on this aspect clearly showed the evident negative effects of UTI attacks where children with reduced kidney size had more frequent urinary tract infections than the ones with normal values ( $\geq 3$ urinary tract infections $75 \%$ vs $32.6 \%$ respectively) (Table 4 ). However, we found the rate of the frequency of urinary tract infections to be similar among cases with decreased and normal renal parenchymal thickness $(35.3 \%$ vs $36.4 \%$ respectively) (Table 5 ).

3. Frequency of stone attacks and age at the diagnosis of stone disease: close follow-up and careful assessment of 
Table 4.

Evaluation of some risk factors according to the renal size of the cases.

\begin{tabular}{|c|c|c|c|}
\hline & $\begin{array}{l}\text { Normal renal size } \\
(>2 S D)(n=46)\end{array}$ & $\begin{array}{l}\text { Reduced renal size } \\
\qquad(<2 S D)(n=4)\end{array}$ & ze $p$ \\
\hline \multicolumn{4}{|c|}{ Duration of breastfeeding (month) } \\
\hline $\begin{array}{l}\text { mean } \pm \text { SD } \\
\text { range (median) }\end{array}$ & $\begin{array}{l}5.8 \pm 5.7 \\
0-24(6)\end{array}$ & $\begin{array}{c}6.5 \pm 11.7 \\
0-24(1)\end{array}$ & 0.406 \\
\hline Formula use $(n, \%)$ & $26(56.5)$ & $3(75)$ & 0.630 \\
\hline \multicolumn{4}{|c|}{ Time of starting solid food (month) } \\
\hline $\begin{array}{l}\text { mean } \pm S D \\
\text { range (median) }\end{array}$ & $\begin{array}{l}6.5 \pm 4.4 \\
4-24(6)\end{array}$ & $\begin{array}{c}10.5 \pm 9 \\
6-24(6.5)\end{array}$ & 0.808 \\
\hline \multicolumn{4}{|c|}{ Duration of breastfeeding (month) } \\
\hline $\begin{array}{l}\text { mean } \pm \text { SD } \\
\text { range (median) }\end{array}$ & $\begin{array}{c}14.2 \pm 10.0 \\
1-42(12)\end{array}$ & $\begin{array}{c}12.0 \pm 12.7 \\
1-30(8.5)\end{array}$ & 0.517 \\
\hline \multicolumn{4}{|l|}{ Frequency of UTI's $(n, \%)$} \\
\hline None & $17(37.0)$ & $1(25.0)$ & 0.432 \\
\hline 1 & $14(30.4)$ & $0(0.0)$ & \\
\hline$\geq 3$ & $15(32.6)$ & $3(75)$ & \\
\hline \multicolumn{4}{|l|}{ Age of first stone (month) } \\
\hline $\begin{array}{l}\text { mean } \pm \text { SD } \\
\text { range (median) }\end{array}$ & $\begin{array}{l}30.5 \pm 4.8 \\
0-138(24)\end{array}$ & $\begin{array}{c}8.5 \pm 10.7 \\
0-24(5)\end{array}$ & 0.064 \\
\hline \multicolumn{4}{|c|}{ Frequency of stone attack (n,\%) } \\
\hline None & $20(43.5)$ & $6(25)$ & 0.812 \\
\hline 1 & $19(41.3)$ & $3(50)$ & \\
\hline$>1$ & $7(15.8)$ & $2(25)$ & \\
\hline Growth retardation $(n, \%)$ & $8(17.4)$ & $3(75)$ & 0.029 \\
\hline \multicolumn{4}{|c|}{ Additional treatment need $(n, \%)$} \\
\hline None & $9(19.6)$ & $1(25)$ & 1.000 \\
\hline ESWL & $29(63)$ & $3(75)$ & \\
\hline ESWL+ & $8(17.4)$ & $0(0)$ & \\
\hline
\end{tabular}

the frequency of stone attacks in infants clearly demonstrated that higher number of stone attacks had also a negative effect on the growth percentile values of the cases. Infants demonstrating a normal body growth course had lower number stone attacks when compared with cases demonstrating evident retardation (> 1 stone attack $18.2 \%$ vs $15.4 \%$ ). Age at the first diagnosis stone disease in growth retarded children was remarkably lower than the ones demonstrating normal growth (median 7 vs 24 months) (Table 3). In orther words, infants with frequent stone attacks beginning at early ages tended to have lower percentile values during long-term follow-up. On the other hand again, evaluation of the renal growth status (kidney size) on this aspect clearly showed the evident negative effect of frequent stone attacks where children with reduced kidney size had higher new stone attacks than the ones with normal values (25\% vs $15.8 \%$ (Table 4). In the same way, frequent stone attacks were associated with reduced renal parenchymal thickness size (> 1 urinary stone attacks $29.4 \%$ vs $9.1 \%$ respectively) (Table 5). Last but not least, our results showed that children presenting with stone disease at relatively younger ages (median 5 vs 24 months, median 12 vs 24 months respectively) tended to have lower kidney size as well as renal parenchymal thickness values when compared with the older ones (Tables 4, 5).

4. Additional stone removal procedures: evaluation of the children with stone removal procedures (40 cases, $80 \%$ ) did not reveal and difference with respect to the body as well as renal growth status in both groups. The
Table 5.

Evaluation of some risk factors according to the renal parenchyma size of the cases.

\begin{tabular}{|c|c|c|c|}
\hline & $\begin{array}{l}\text { Normal renal } \\
\text { parenchymal } \\
\text { thickness } \\
(n=33)\end{array}$ & $\begin{array}{l}\text { Reduced renal } \\
\text { parenchymal } \\
\text { thickness } \\
(<2 S D)(n=17)\end{array}$ & p \\
\hline $\begin{array}{l}\text { Duration of breastfeeding (month) } \\
\text { mean } \pm \mathrm{SD} \\
\text { range (median) }\end{array}$ & $\begin{array}{l}6.3 \pm 6.2 \\
0-24(6)\end{array}$ & $\begin{array}{l}5.1 \pm 6.3 \\
0-24(3)\end{array}$ & 0.426 \\
\hline Formula use $(n, \%)$ & $17(51.5)$ & $12(70.6)$ & 0.321 \\
\hline $\begin{array}{l}\text { Time of starting solid food (month) } \\
\text { mean } \pm S D \\
\text { range (median) }\end{array}$ & $\begin{array}{c}9.0 \pm 5.7 \\
4-24(6)\end{array}$ & $\begin{array}{c}7.7 \pm 2.1 \\
6-12(7.7)\end{array}$ & 0.668 \\
\hline $\begin{array}{l}\text { Duration of breastfeeding (month) } \\
\quad \text { mean } \pm \mathrm{SD} \\
\text { range (median) }\end{array}$ & $\begin{array}{c}14.6 \pm 8.8 \\
1-32(14.5)\end{array}$ & $\begin{array}{c}12.9 \pm 12.6 \\
1-42(8)\end{array}$ & 0.228 \\
\hline $\begin{array}{l}\text { Frequency of UTI's }(n, \%) \\
\text { None } \\
1 \\
\geq 3\end{array}$ & $\begin{array}{l}10(30.3) \\
11(33.3) \\
12(36.4)\end{array}$ & $\begin{array}{l}8(47.1) \\
3(17.6) \\
6(35.3)\end{array}$ & 0.427 \\
\hline $\begin{array}{l}\text { Age of first stone (month) } \\
\quad \text { mean } \pm S D \\
\text { range (median) }\end{array}$ & $\begin{array}{c}30.7 \pm 31.5 \\
0-138(24)\end{array}$ & $\begin{array}{c}25.2 \pm 32.9 \\
0-132(12)\end{array}$ & 0.281 \\
\hline $\begin{array}{l}\text { Frequency of stone attack }(n, \%) \\
\text { None } \\
1 \\
>1\end{array}$ & $\begin{array}{c}15(45.5) \\
15(45.5) \\
3(9.1)\end{array}$ & $\begin{array}{l}6(25) \\
3(50) \\
5(29.4)\end{array}$ & 0.229 \\
\hline Growth retardation $(n, \%)$ & $5(15.2)$ & $6(35.3)$ & 0.151 \\
\hline $\begin{array}{l}\text { Additional treatment need } \\
\text { None } \\
\text { ESWL } \\
\text { ESWL+ other }\end{array}$ & $\begin{array}{l}6(18.2) \\
21(63.6) \\
6(18.2)\end{array}$ & $\begin{array}{l}4(23.5) \\
11(64.7) \\
2(11.8)\end{array}$ & 0.913 \\
\hline
\end{tabular}

interventions seemed to have no negative effect on these values and we may quote that removal of the stone from the kidney may have a protective effect on this aspect by lowering risk of obstruction and infection during the course of the disease. But the procedures themselves did not seem to affect the growth status of these children (Tables 3-5).

\section{Discussion}

With an incidence of $1-5 \%$, children constitute only a small number of all patients with urolithiasis. However, pediatric urolithiasis is still an endemic problem in developing countries where the composition of stones depends mainly on socioeconomic conditions, geography and dietary habits $(1,2,15)$. Thus, at least in these regions, pediatric stone disease is an important health care problem because of the high recurrence rate and the subsequent threat on renal function and possible decrease in the quality of life (24-27). Infantile nephrolithiasis is not a rare situation and the diagnosis of small calculi by well defined pediatric ultrasonography has been increasing in recent years. There are several studies on pediatric stone disease which include children younger than 1 year. Majority of these studies have been reported from countries like Turkey, Armenia, United Kingdom, Iceland, Iran, Iraq, and Italy where the disease is still relatively common $(3-11,21,26)$. Published data showed that like in adults, greater than $75 \%$ of all uri- 
nary tract calculi in children are composed of calcium oxalate or calcium phosphate $(3,6,7,28-30)$. The objective of stone management in children should include complete stone clearance, prevention of new stone formation and re-growth, preservation of renal function, control of urinary tract infection, and correction of both the anatomic abnormalities and underlying metabolic disorders $(1,3,13,28)$.

Long-term post-operative follow-up is mandatory, especially after using newer stone management modalities due to the higher stone recurrence rates in this specific population (18-20, 31-33). Regarding this issue; the disease has been found to be associated with considerable morbidity, with recurrence rates ranging from 6.5 to $44 \%$ with a mean recurrence interval of $3-6$ years $(3,13$, $31,34)$. Without follow-up and medical intervention, stone recurrence rates have been reported to be as high as $50 \%$ within 5 or 6 years $(13,31)$. In our previous study, we were able to evaluate 91 children with a mean follow-up of 38.2 months and report a $4.2 \%$ recurrence rate (17). In their original study, Rivzi et al. evaluated a huge number of children (n:1440) and demonstrated a $2 \%$ recurrence rate during a 13-year follow-up period (35). Taking high incidence of metabolic abnormalities, anatomical anomalies and other certain problems into account; stone disease may have a recurrent course in most of the children and unfortunately there are limited data published in the literature evaluating the natural course of pediatric urinary stone disease on this aspect on a long-term basis (18-20, 31-33).

On the other hand, by giving a special emphasis on the risk factors for stone recurrence in children, Schwarz and Dwyer concluded that children with upper urinary stones have a risk of recurrence similar to the risk reported in adult series (20). They also concluded that no specific risk reduction was related to the outcomes of metabolic risk evaluation tests. Regarding the impact of stone disease on renal growth and pysical development again; the Authors could not observe any evidence regarding the negative impact of these factors. On the other hand, as a chronic disease and stress for the growing body of children, stone disease and related disorders (infection, obstruction, colic pain attacks etc.) may well affect the physical growth of the children suffering from this problem. Recurrent urinary tract infections with or without obstruction are the most important parameters affecting body growth. In this present study, regarding the impact of UTI on the growth status of children; while $54.5 \%$ of the children with growth retardation demonstrated recurrent UTI; of the 39 cases with normal growth status only $30.8 \%$ demonstrated recurrent UTI ( $\geq 3$ attacks) which might pose a possible additional adverse effect on the clinical course of stone disease in these children during long-term follow-up.

Evaluation of our current findings clearly showed the evident effects of some certain factors on the physical as well as renal growth status of the infants which should be monitored in a close manner. Our data demonstrated that thorough a very close follow-up and approptiately taken measures, the possible growth retardation (which has been reported in limited number of studies) as well as renal growth problems could be avoided in a success- ful manner. In our group, infants receiving longer period of breast feeding without formula addition did seem to have a higher rate of normal growth percentile values then compared with the other children. Again, higher frequency of UTI as well as stone attacks affected the growth status of the infants with stones in a remarkable manner than the others.

Taking the limited data published in the literature so far into account; we believe that our study contains valuable and important information regarding the natural clinical course of stone disease in infants, with an emphasis on the feeding status that may closely affect this course with lower frequency of UTI and stone attacks. Delayed or later initiation of the formula with long-lasting breast feeding seemed to be highly relevant with these events that may affect the growth status of infants. This special effect of breast feeding could be explained by its possible reducing effect on the urinary tract infections. Ajetunmobi et al. found a greater risk of hospitalization for all infections including UTIs among formula-fed infants compared with breastfed ones (36). Marild et al. showed that longer duration of exclusive breast feeding was associated with a lower risk of febrile UTI in children (37). It was suggested that the antiadhesive oligosaccharides, unspecific antibacterial lactoferrin, secretory immunoglobulin antibodies in breast milk could be effective in these special protective effects supplied by human milk $(37,38)$. Our study may have some limitations. One major limitation of the study may be the relatively small number of children included in both groups. Again, the possible individual effect of medical management on the correction of above mentioned parameters could also have been evaluated during the long-term follow-up.

However taking the highly limited data reported in the literature on this subject paticularly in this specific population into account, we believe that our current findings will be contributive enough on this aspect.

\section{Conclusions}

Accumulated data in the literature so far demonstrate that due to the high likelihood of predisposing factors resulting in higher stone recurrence and re-growth rates; all children with urinary stone disease should be followed closely with regular visits. In the light of our findings we may implicate that all infants with stone disease should be followed closely with respect to the body as well as kidney growth status. Breast feeding is a critical factor that may affect the child's growth status by lowering the risk of UTI as well as new stone attacks. However, we believe that further studies with larger number of cases are certainly needed in order to outline the possible effects of the parameters evaluated in this study on the clinical course of urolithiasis in this specific group of cases.

\section{Ethical approval}

All procedures performed in studies involving human participants were in accordance with the ethical standards of the institutional research committee and with the 1964 Helsinki declaration and its later amendments or comparable ethical standards. 


\section{REFERENCES}

1. Faerber GJ. Pediatric urolithiasis. Review Curr Opin Urol. 2001; 1:385-9.

2. Sarica K. Medical aspect and minimal invasivetreatment of urinary stones in children. Arch Ital Urol Androl. 2008; 80:43-9.

3. Bastug F, Gunduz Z, Tulpar S, et al. Urolithiasis in infants: evaluation of risk factors. World J Urol. 2013; 31:1117-22.

4. Guven AG, Koyun M, Baysal YE, et al. Urolithiasis in the first year of life. Pediatr Nephrol. 2010; 25:129-34.

5. Mohamed J, Riadh M, Abdellatif N. Urolithiasis in infants. Pediatr Surg Int. 2007; 23:295-9.

6. Ali SH, Rifat UN. Etiological and clinical patterns of childhood urolithiasis in Iraq. Pediatr Nephrol. 2005; 20:1453-7.

7. Coward RJ, Peters CJ, Duffy PG, et al. Epidemiology of paediatric renal stone disease in the UK. Arch Dis Child. 2003; 88:962-5.

8. Edvardsson V, Elidottir $H$, Indridason OS, et al. High incidence of kidney stones in Icelandic children. Pediatr Nephrol. 2005; 20:940-4.

9. Ozokutan BH, Kucukaydin M, Gunduz Z, et al. Urolithiasis in childhood. Pediatr Surg Int. 2000; 16:60-3.

10. Safarinejad MR. Urinary mineral excretion in healthy Iranian children Pediatr Nephrol. 2003; 18:140-4.

11. Sarkissian A, Babloyan A, Arikyants N, et al. Pediatric urolithiasis in Armenia: a study of 198 patients observed from 1991 to 1999. Pediatr Nephrol. 2001; 16:728-32.

12. Spivacow FR, Negri AL, Del Valle EE, et al. Metabolic risk factors in children with kidney stone disease. Pediatr Nephrol. 2008; 23:1129-33.

13. Sarica K. Pediatric urolithiasis: etiology, specific pathogenesis and medical treatment. Urol Res. 2006; 34:96-101.

14. Pietrow PK, Pope JC, Adams MC, et al. Clinical outcome of pediatric stone disease. J Urol. 2002; 167:670-3.

15. Kroovand RL. Pediatric urolithiasis. Urol Clin North Am. 1997; 24:173-85.

16. Stapleton FB. Clinical approach to children with urolithiasis. Semin Nephrol. 1996; 16:389-97.

17. Erbagcı A, Erbagci BA, Yllmaz M, et al. Pediatric Urolithiasis. Scand J Urol Nephrol. 2003; 37:129-33.

18. Koyuncu H, Yencilek F, Erturhan S, et al. Clinical course of pediatric urolithiasis: Follow-up data in a long-term basis. Int Urol Nephrol. 2011; 43:7-13.

19. Van Dervoort K, Wiesen J, Frank R, et al. Urolithiasis in pediatric patients: A single center study of incidence, clinical presentation and outcome. J Urol. 2007; 177:2300-05.

20. Schwarz RD, Dwyer NT. Pediatric kidney stones: Long-term outcomes. Urology. 2006; 67:812-6.

21. Gökçay G, Furman A, Neyzi O. Updated growth curves for Turkish children aged 15 days to 60 months. Child Care Health Dev. 2008; 34:454-63.

22. Neyzi O, Fuman O, Bundak R, et al. Growth references for Turkish children aged 6-18 years. Acta Pediatr. 2006; 95:1635-41.

23. Kadioglu A. Renal measurements, including length, parenchymal thickness, and medullary pyramid thickness, in healthy children: what are the normative ultrasound values? AJR Am J Roentgenol. 2010; 194:509-15.

24. Azili MN, Ozturk F, Inozu M, et al. Management of stone disease in infants. Urolithiasis 2015; 43:513-9.
25. Elmacı AM, Ece A, Akın F. Pediatric urolithiasis: metabolic risk factors and follow-up results in a Turkish region with endemic stone disease. Urolithiasis 2014; 42:421-6.

26. Alpay H, Gokce I, Özen A, et al. Urinary stone disease in the first year of life: is it dangerous? Pediatr Surg Int. 2013; 29:311-6.

27. Copelovitch L. Urolithiasis in children: medical approach. Pediatr Clin North Am. 2012; 59:881-96.

28. Cohen TD, Ehreth J, King LR, et al. Pediatric urolithiasis: medical and surgical management. Urology 1996; 47:292-305.

29. Milliner DS, Murphy ME. Urolithiasis in pediatric patients. Mayo Clin Proc. 1993; 68:241-4.

30. Bak M, Ural R, Agin H, et al. The metabolic etiology of urolithiasis in Turkish children. Int Urol Nephrol. 2009; 141:453-60.

31. Schwarz RD, Dwyer NT. Pediatric kidney stones: long-term outcomes. Urology 2006; 67: 812-6.

32. Dursun I, Poyrazoglu H, Dusunsel R, et al. Pediatric urolithiasis: an 8-year experience of single centre. Int Urol Nephrol. 2008; 40:3-9.

33. Tabel Y, Akin IM, Tekin S. Clinical and demographic characteristics of children with urolithiasis: single center experience from eastern Turkey. Urol Int. 2009; 83:217-21.

34. Noe HN. Hypercalciuria and pediatric stone recurrences with and without structural abnormalities. J Urol. 2000; 164:1094-6.

35. Rizvi SA, Naqvi SA, Hussain Z, et al. Pediatric urolithiasis: developing nation perspectives. J Urol. 2002; 168:1522-5.

36. Ajetunmobi OM, Whyte B, Chalmers J, et al. Breastfeeding is associated with reduced childhood hospitalization: evidence from Scottish Birth Cohort (1997-2009). J Pediatr. 2015; 166:620-5.

37. Marild S, Hansso U, Jodal U, et al. Protective effect of breast feeding against urinary tract infection. Acta Paediatr. 2004; 93:164-8.

38. Coppa G, Gabrielli O, Giorgi P, et al. Preliminary study of breastfeeding and bacterial adhesion to uroepithelial cells. Lancet 1990; 335:569-71.

\section{Correspondence}

Kemal Sarica, MD

saricakemal@gmail.com

Kubilay Sabuncu, MD

kubilaysabuncu@yahoo.com

Utku Can, MD

utkucan99@yahoo.com

Ayşe Buz, Nurse

aysebuz@hotmail.com

Bilal Eryildirim, MD (Corresponding Author)

ilaleryildirim@yahoo.com

Dr. Lutfi Kirdar Training and Research Hospital Urology Clinic,

Istanbul, Turkey

Tecerdagi Cad. Yakutlar Sitesi G/11 - Kartal, Istanbul, Turkey

Fatma Narter, $M D$

fatmakaya06@yahoo.com.tr

Dr. Lutfi Kirdar Training and Research Hospital Pediatric Clinic,

Istanbul, Turkey

Ahmet Akca, MD

ahmtakca@yahoo.com

Dr. Lutfi Kirdar Training and Research Hospital Radiology Clinic, Istanbul, Turkey

H. Nese Sarica, MD

nesesarica@yahoo.com

Pediatrician, Medistate Hospital, Istanbul, Turkey 